\title{
Infected right ventricular myxoma and pulmonary valve endocarditis
}

\author{
Vincent Chan, MD, John P. Veinot, MD, Mark Hynes, MD, Harry Lapierre, MD, and Marc Ruel, MD, MPH, Ottawa, \\ Ontario, Canada
}

$\mathrm{I}$ nfected right-sided cardiac myxoma is uncommon, and we describe here the first reported case seen in conjunction with pulmonary valve endocarditis.

\section{Case Summary}

A 44-year-old man with a history of intravenous drug use, hepatitis C, and bipolar disease came to hospital with septic shock and hypoxia requiring low-dose vasopressor support and high-flow oxygen by face mask. Echocardiographic examination revealed a 4.3-cm solid, hyperechoic nodule in the right ventricle. He was treated with intravenous trimethoprim/sulfamethoxazole, vancomycin, and gentamicin for Streptococcus viridans, which had been isolated from the blood and sputum. Computerized tomographic imaging revealed no evidence of any masses in the abdomen or thorax, although there was evidence of pulmonary microemboli and bilateral empyemas.

The patient was treated with antibiotics for 6 weeks, with no change noted in the size of the right ventricular mass on serial echocardiography. During this period, the patient's condition was clinically stable; however, persistent fever and elevated white blood cell count $(>18,000$ cells $/ \mu \mathrm{L})$ prompted cardiac surgical consultation.

The patient was subsequently taken to the operating room, where the initial intraoperative echocardiography confirmed a solid hyperechoic mass originating in the right ventricle (Figure 1), which was prolapsing across an abnormal pulmonic valve and causing pulmonic insufficiency. An attempt was made to remove the mass through the right atrium. Because of the size of the mass and concern of damaging the tricuspid valve, however, a right ventriculotomy was performed and the mass removed en bloc. The ventriculotomy was closed with running 3-0 Prolene sutures (Ethicon, Inc, Somerville, NJ) and felt.

During weaning from cardiopulmonary bypass, transesophageal echocardiography showed severe pulmonary insufficiency secondary to a flail anterior leaflet that had previously been obscured by the ventricular mass. The pulmonary valve was then replaced with a No. 25 Hancock II bioprosthesis (Medtronic, Inc, Minneapolis, Minn). The patient was weaned from cardiopulmonary bypass without difficulty, had an uncomplicated postoperative course, and remains alive and well.

From the University of Ottawa Heart Institute, Ottawa, Ontario, Canada.

Received for publication March 13, 2007; accepted for publication March 22, 2007.

Address for reprints: Marc Ruel, MD, MPH, University of Ottawa Heart Institute, Division of Cardiac Surgery, 40 Ruskin St, Suite 3403, Ottawa, ON K1Y 4W7, Canada (E-mail: mruel@ottawaheart.ca).

J Thorac Cardiovasc Surg 2007;134:248-9

$0022-5223 / \$ 32.00$

Copyright $\odot 2007$ by The American Association for Thoracic Surgery doi:10.1016/j.jtcvs.2007.03.026
The final pathology report confirmed infection of a tricuspid pulmonary valve with gram-positive cocci. The right ventricular mass, which measured $8 \times 5 \times 3 \mathrm{~cm}$, was found to be an infected benign cardiac myxoma with necrosis and numerous gram-positive cocci (Figure 2).

\section{Discussion}

Cardiac myxomas represent approximately half of all benign cardiac tumors. The incidence in the general population is approximately $0.2 \% .^{1}$ Right-sided myxomas are rare, occurring in fewer than a fourth of all cases. ${ }^{1}$

The most commonly described complications of myxoma include obstruction and embolization. Rarely has infection of a myxoma been described. In 1998, Revankar and Clark ${ }^{2}$ reported 34 previously described cases of infected myxoma. Only 6 were right sided. ${ }^{2}$ This case represents the 42 nd reported infected myxoma and 8th reported right-sided infected myxoma.

Revankar and Clark ${ }^{2}$ also described clinical criteria for the diagnosis of infected cardiac myxoma. A definitive diagnosis of infected myxoma can be made if the diagnosis of myxoma is confirmed by pathologic examination and either organisms are isolated from the myxoma, organisms are seen on histologic examination, or positive blood cultures are documented in the presence of inflammatory changes noted on pathologic examination.

The complications occurring from infected myxoma are similar to those of uninfected myxoma, although infected myxomas are more prone to embolization. ${ }^{3}$ Contiguous spread of infection has also been documented. There are rare reports of infected left atrial myxomas causing mitral valve endocarditis. ${ }^{4}$ There are no reports of infected right ventricular myxomas occurring in the presence of pulmonary valve endocarditis, which itself is rare and occurs most commonly in patients who use intravenous drugs or have indwelling catheters. ${ }^{5}$

In light of this patient's history of intravenous drug use, it is unclear whether the primary infection was of the pulmonary valve or the right ventricular myxoma. To our knowledge, this report describes the first case of an infected right ventricular tumor occurring with pulmonary valve endocarditis.

\section{References}

1. Reardon MJ, Smythe WR. Cardiac neoplasms. In: Cohn LH, Edmunds LH, editors. Cardiac surgery in the adult. 2nd ed. New York: McGrawHill; 2003. p. 1373-1400.

2. Revankar SG, Clark RA. Infected cardiac myxoma. Case report and literature review. Medicine (Baltimore). 1998;77:337-44.

3. Bough EW, Johnson EE, Zacks SI, Boden WE, Mandel A, Medeiros AA, et al. Echocardiographic diagnosis of an infected myxoma in an atypical location. Am Heart J. 1987;113:1031-2.

4. Quigley RL, Meursing DF, Rossman MI. Left atrial myxoma and mitral valve endocarditis - a cause and effect: a case report. Heart Surg Forum. 2006;9:E486-7.

5. Ramadan FB, Beanlands DS, Burwash IG. Isolated pulmonic valve endocarditis in healthy hearts: a case report and review of the literature. Can J Cardiol. 2000;10:1282-8. 

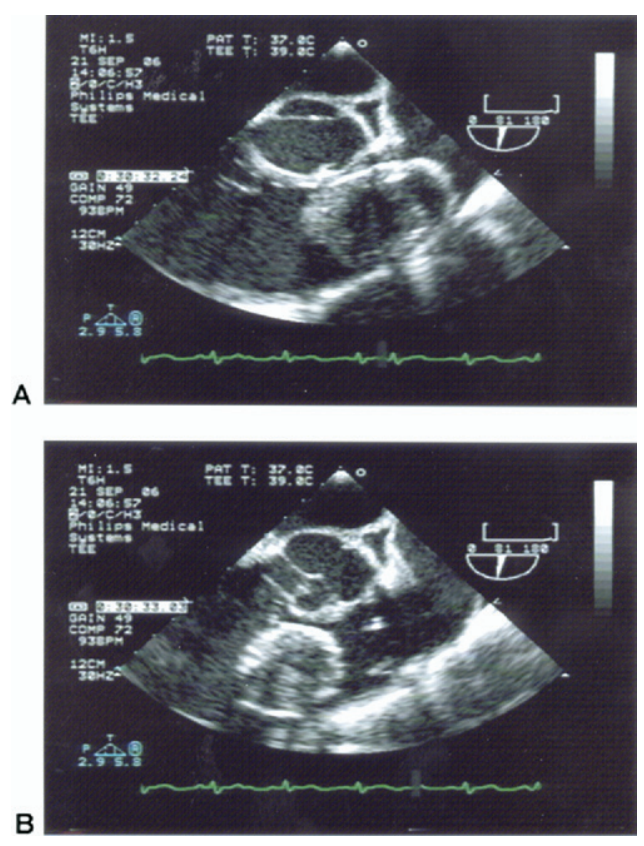

Figure 1. Myxoma visualized in ventricular systole (A) and diastole (B).
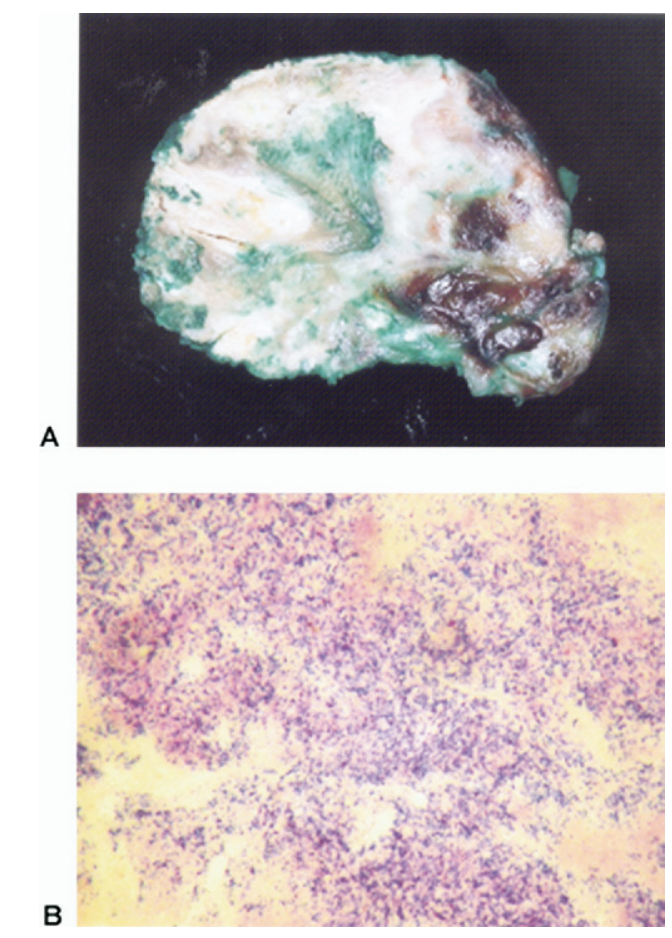

Figure 2. A, Gross image of infected benign cardiac myxoma. Myxoma has solid appearance with rounded contour. Areas of mottling and necrosis, unexpected in benign myxoma, correspond to regions with bacterial invasion. B, Gram stain of cardiac myxoma shows numerous gram-positive cocci. 